\title{
The Impact of Population Growth on Economic Growth: Evidence from Ethiopia using ARDL Approach
}

\author{
Kidane Alemu \\ College of Business and Economics, Dambi Dollo University, Ethiopia
}

\begin{abstract}
There is no consensus on the impact of population on economic growth as economists are torn with different varying theories and empirical findings. This study therefore analyzed the impact of population growth on economic growth in Ethiopia using annual time series data over the period 1980/81-2018/19 in a multivariate framework. The study is theoretically based on neo-classical growth model and empirically on the ARDL Methodology along with Philips Peron Unit root tests and other important time series techniques. Results from ARDL Bounds testing indicated that there exists co-integration among population, export, import, trade openness, government expenditure and economic growth for real GDP is taken as dependent variable. The empirical model revealed population growth, export growth and import growth having significant positive impact on economic growth of Ethiopia both in the short-run and long-run while trade openness has significant negative effect on same and government expenditure growth has insignificant impact. Moreover, Toda-Yamamoto and DoladoLutkepohi as well as Innovative Accounting Techniques (that is, IRFs and FEVD) approaches to Granger causality analysis showed the existence of strong bidirectional causality between population growth and economic growth. The implication of the finding is that population is an asset rather than a burden for the country, and therefore; a carefully planned and productive population advance along with well managed macro variables would sustain the growth of the its economy.
\end{abstract}

Keywords: ARDL, Causality, Economic Growth, Ethiopia, Population Growth

DOI: $10.7176 / \mathrm{JESD} / 11-3-02$

Publication date: February $29^{\text {th }} 2020$

\section{Introduction}

Population growth can have several effects on the economic expansion and performance of a country. On the other hand, Population growth and economic growth are highly interrelated since they affect each other. Their relation has attracted the attention of economists since economics was established as self-discipline (Jhingan,2002)

Although the world has witnessed unprecedented population growth during the last 50 to 60 years, faster growth than any other 50 to 60 -year period, the rate of growth has been decelerating since its peak rate of 2.3 percent yearly in 1960 to 1.3 percent in 2005 to an expected 0.8 percent in 2025 and 0.4 percent in 2050 . This shows reduction in the growth rate of population resulted from factors such as: urbanization, greater economic aspirations, increased female education and labor force participation, and more accessibility to family planning (Martin, 2009).

The current world population is 7.5 billion with the growth rate of $1.14 \%$ per year. From this total, about eighty-one percent live in Less Developed Countries. Africa has the fastest growing population in the world. Currently, the total population of Africa is about 1.2 billion people, which will double it after 29 years and it is being estimated at about 2.4 billion in 2050 . Consequently, this might hinder the achievement of planned family which is very significant to moderate population growth in the continent (Todaro, 2004).

According to latest census figure of Ethiopian CSA, the total population in Ethiopia was estimated at 102.4 million in 2016. Looking back, in the year of 1960, Ethiopia had a population of 22.2 million people. The population of Ethiopia represents 1.23 percent of the world's total population which arguably means that one person in every 82 people on the planet is a resident of Ethiopia (Trading Economics, reviewed on December $22 / 2018$ ). However, this total figure was equally associated with unemployment rate of 16.80 percent. Although the progress towards eliminating extreme poverty, Ethiopia remains one of the poorest countries in the world .Changes in rain fail associated with worldwide weather patterns resulted in the worst drought in 30 years in 2015-16, creating food insecurity for millions of Ethiopians (CIA WFB, 2018)

Obviously, it is witnessed that the world, the continental and the national population is increasing with changing economic system despite the projected decreases in its growth rates. However, there is no agreement on the impact of such a growing population on economic growth. As a result, the debate on the relationship between population growth and economic growth has been undergoing and it varies across countries (Obere et al., 2013)

The first theory view population growth as a factor that adversely affects economic growth. The second theory states that population growth stimulates economic growth. While the views of a third school is that population growth is a neutral factor in economic growth and is determined outside the standard growth models 
(Obere et al., 2013).The worldwide empirical findings are also available with diverging conclusions in line with the above three compelling theories on the topic. In Ethiopia, to the researcher's best knowledge few scant studies (egg. see, Kasahun, 2014) have been carried out on the topic and with inconclusive results.

Therefore, the main objective of this study was to empirically determine the relationship between population growth and economic growth in Ethiopia during the periods 1980/81-2017/18.

\section{Methodology of the Study}

The study was designed to be hypothesis testing (that is, quantitative research).It used secondary data obtained from Ministry of Finance and Economic Development, National Bank of Ethiopia and Central Statistical Authority of Ethiopia. And in order to avoid data inconsistency problem associated with different base year price while computing real GDP, the study used the real GDP deflated by MoFED at 2011 year constant price ;and attempts has been made to cross-check for the validity of the data obtained .

\subsection{Conceptual Framework and Model Specification}

The empirical model adopted to examine the long run and short run relationship between population growth and economic growth is an Autoregressive Distributed Lag (ARDL) model (Bound testing methodology) proposed by Pesaran and Shin (1997 and 1999) and Pesaran et al. (2001).

The theoretical foundation of the study is based on neoclassical growth model following Kassahun (2014), Nwosu et al. (2014) and Gideon et al. (2013). Thus, the following economic growth function was specified by incorporating other determinants of growth:

$R G D P$ growth $=f($ population, exports, imports, tradeopenness, goverment exp enditure)..

All variables were transformed into natural log in order to remove or reduce considerably any Heteroscedasticity in the residuals of the estimated model following Gujarati(2004). The log-log form specification also enabled the researcher to interpret the coefficient of the dependent variable directly as elasticity with respect to the independent variables as of Sarmad(1988) (cited in Nesredin,2015). Therefore, the econometric version of equation (3.1) with the natural log has been specified as below:

$$
\ln R G D P t=\beta 0+\beta 1 \ln X t+\beta 2 \ln M t+\beta 3 \ln G t+\beta 4 \ln P o P t+\beta 5 \ln O P n t+\varepsilon t \ldots . .(3.2)
$$

Where:RGDPt is the real GDP at time t,PoPt is the total number of Ethiopian population at time t,Gt is government expenditure at time t,Xt is export in the Economy at time t,Mt is import at time t,OPnt is trade openness at time $t$; and $\beta_{0}$ is the intercept term of the model which depicts the level of economic growth that would exist with zero levels of the repressors. $B_{K}$ 's $(i=1,2,3,4,5)$ are the weights of the each explanatory variables in the model. Thus, $\beta 1$ up to $\beta 5$ measure the partial elasticity's of real GDP with respect to the each respective independent variable. Whereas $\varepsilon t$ is stochastic variable at time $t$ which accommodates the influence of all other determinants of economic growth not included in the model. It is usually called as error term and is assumed to be normally and independently distributed with zero mean and constant variance, and $t$ is the time variable and $\ln$ is natural $\log$.

\subsection{Measurement of Variables and Expected Signs}

Real GDP (RGDP): since most economists (see for egg. Mankiw, 1992); Barro, 1993 and 2013)) argue that economic growth can be best measured using growth in real GDP; it is included in the model as a dependent variable to measure economic growth. The data is given in millions of Ethiopian Birr.

Population (+ or -): is the main explanatory variable of this study. It is the total number of people living in Ethiopia during the study period. The data is obtained from Central Statistical Authority of Ethiopia (CSA) and it is given in millions. Kassahun(2014) examined the impact of the Ethiopia's population on its economic performance over the period 1970/71-2004/05. The study concluded that population issue related to economic growth is very controversial for the reason that it find it has negative impact on the economic growth in the short run but positive impact in the long run. Thus, positive or negative sign was expected for this variable by this study.

Export (+):It is believed that export is one of the macroeconomic determinants of economic growth. The data is obtained from MoFED and is given in millions of Ethiopian Birr. Export positively determines the growth of Ethiopian Economy (Haylegiorgis,2012;Senait,2014 and Woynishet,2014),thus; this study also expected positive sign.

Import (+): Import also has theoretical importance for economic growth. Studies such as Bethelehem(2017) and Alemayehu (2013) used a multivariate models and found significant positive relationship between import and economic growth in Ethiopia. Thus, this study also expected positive sign for import.

Trade openness $(+)$ : in this study, $(\mathrm{X}+\mathrm{M} / \mathrm{RGDP})$ approach measurement is used to quantify the trade openness of Ethiopia. Theoretically, with trade liberalization this measurement is expected to increase over time. Estubdink (2014) founded trade openness having insignificant negative impact of trade openness on the 
economic growth of the country. However, Yetsedaw (2017) found that trade liberalization as one of the most important significant variable to determine economic growth positively in Ethiopia. This study expected positive and significant sign for this variable to ascertain the recent result.

Government expenditure $(+)$ : Theoretically, specifically in Keynesian theory, government expenditure is advocated as the most determinant of economic growth and as one of fiscal policy tool. However, most of studies, for instance, Kojo(2012) and Dereje (2012) among others conclude that government expenditure has positive but insignificant impact on the economic growth of the country. They reasoned that it this is due to the un-transparent and unaccountable behavior of the government. Thus, this study also expected positive and insignificant effect for this variable.

\subsection{Econometric Estimation Techniques and Procedures}

\subsubsection{Unit Root Test}

A stochastic process is said to be stationary if its mean and variance are constant over time and the value of the covariance between the two time series depends only on the distance or lag between the two time periods ,but not the actual time at which the covariance is computed(Gujirati,2004).

If the time series is not stationary, it is called non-stationary time series which have a time varying mean or a time varying variance or both. In this case it is impossible to use simple Ordinary List Square (OLS) to estimate the long-run linear relationships between variables. If we do so, it would lead to spurious regression (non-sense economic analysis) where R-squared is very high (that is, in excess of 0.9), the usual $t$ and F-statistics look significant and valid but not in fact (Gujirati,2004; Vebrek ,2004)

Granger (1969) suggested that a coefficient of determination greater than the Durbin-Watson statistics $\left(\mathrm{R}^{2}>\right.$ d) is a good rule of thumb to suspect that the estimated regression is spurious. Once detected, a unit root problem can be solved by differencing the data set as to (Gujirati, 2004).If the variable is stationary without differencing, then it is integrated of order zero, I(0). And a variable is said to be integrated of order one, or I(1), if it is stationary after differencing once, or of order two, I(2), if differenced twice.

Although applying ARDL methodology does not require pre-testing for order of integration, unit root test is conducted in this study so as to ride out from the problem of spurious regression and so as to check that none of the series is I(2) since the application of ARDL model is not justified with such order; and the Philip Perron (PP) test is used among others since it has greater power than the Augmented Dickey-Fuller (ADF) test.

The Dickey-Fuller test involves fitting the regression model:

$\Delta X t=\rho x t-1+($ cons $\tan t$, time trend $)+\varepsilon t$.

$\Delta x t=\alpha+\beta t+\phi x t-1+\sum \gamma i \Delta x t-i . .+\varepsilon t$.

ere $\mathrm{i}=2,3,4 \ldots \mathrm{n}$. (3.4) called augmented Dickey-Fuller $(A D F)$ test. It accounts for the serial correlation problem that presents in (3.3) by including lags of the first differences of xt. The Phillips- Perron test involves fitting (3.5) as below, and the results are used to calculate the test statistics:

$x t=\omega x t-1+($ cons $\tan t$, time trend $)+\varepsilon t$

In (3.3) et is assumed to be $\mathrm{I}(0)$ and may be heteroskedastic but in (3.5), the PP test corrects for any serial correlation and Heterokedasticity in the errors(ct) non-parametrically by modifying the Dickey Fuller test statistics.

Phillips and Peron's test statistics can be viewed as Dickey-Fuller statistics that have been made robust to serial correlation by using the Newey-West (1987) Heterokedasticity and auto-correlation-consistent covariance matrix estimator.

Under the null hypothesis that $\rho=0$, the PP $\mathrm{Zt}$ and $\mathrm{Z} \pi$ statistics have the same asymptotic distributions as the ADF t-statistic and normalized bias statistics. And the advantages of the PP tests over the ADF tests are:(1) the PP tests are robust to general forms of Heterokedasticity in the error term (2) the user does not have to specify a lag length for the test regression.

\subsubsection{Co-integration Test using ARDL (Bounds) Testing Approach}

Co-integration means that despite being individually non-stationary, a linear combination of two or more time series can be stationary (Gujarati, 2004). And a number of methods for testing co-integration have been proposed in the economic literature. The most common are the Engle-Granger procedure, the Johansen's co-integration procedure and Autoregressive Distributed Lag (ARDL) method of co-integration.

ARDL is the most recent and the most popular in econometric literatures because of its features and advantages:(1)It can be applied irrespective of the order of integration as )long as $\mathrm{d}_{\max }$ is less than two. That is, the ARDL methodology is applicable no matter even if there is mixed order of I (0) and I(1) variables within the series(2)It provides statistically significant result in small samples unlike the Johansen co-integration techniques which require large data samples for validity(3)It gives unbiased and valid estimates of the long run model even when some of the repressors are endogenous(4)It involves just a single-equation set-up which makes it simple to 
implement and interpret(5)Different variables can be assigned different lag-lengths as they enter the model(5)A dummy variable can be included in the co-integration test process, which is not permitted in Johansen's method To overcome the limitations of the other two convectional approaches (Pesaran \& Shin ,1999; Pesaran et al.,2001)

Thus, the following ARDL model has been specified in order to test the long-run relationships (co-integration) between variables:

$$
\begin{aligned}
& \Delta \ln R G D P t=(\beta 0, \text { trend })+\sum_{i=1}^{p} \beta 1 \Delta \ln R G P t-1+\sum_{i=1}^{p} \beta 2 \Delta \ln \text { PoPnt }-i+\sum_{i=1}^{p} \beta 3 \Delta \ln \text { OPnt }-i \\
& +\sum_{i=1}^{p} \beta 4 \Delta \ln G t-i+\sum_{i=1}^{p} \beta 5 \Delta \ln X t-i+\sum_{i=1}^{p} \beta 6 \Delta \ln M t-1+\varpi 0 \ln R G D P t-1+\varpi 1 \ln P o P t-1 \\
& \varpi 2 \ln O P n t-1+\varpi 3 \ln G t-1+\varpi 4 \ln X t-1+\varpi 5 \ln M t-1+\varepsilon t
\end{aligned}
$$

Where all variables are as defined before; and $\varpi 0, \varpi 1, \varpi 2, \varpi 3, \varpi 4$ and $\varpi 5$ are long run coefficients that measure long run relationships; whereas $\beta 0$ is the intercept and $\beta 1, \beta 2, \beta 3, \beta 4, \beta 5$ and $\beta 6$ are short run coefficients that measure the short run relationships, $\varepsilon t$ is an error term and $p$ denotes the optimal lag length of the auto regressive process, $\Delta$ is difference operator and trend is the time trend of the model. From equation (3.6), we first test the null hypothesis of no co-integration, $\mathrm{H0}$ : $\varpi 0=\varpi 1=\varpi 2=\varpi 3=\varpi 4=\varpi 5$ against the alternative one, that is, $\mathrm{H}: \varpi 0 \neq \varpi 1 \neq \varpi 2 \neq \varpi 3 \neq \varpi 4 \neq \varpi 5$ using the F-test with upper and lower critical values that are calculated automatically and reported after the ARDL estimate results. To this end, the order of the lag distribution function should be selected using among the standard information criteria such as Akakie Information Criterion (AIC) and Schwaretz Bayesian Criterion (SBC)

The decision rule is that, if the computed F-statistics is higher than the appropriate upper bound of the critical value, the null hypothesis of no co-integration will be rejected. If it is below the appropriate lower bound, the null hypothesis cannot be rejected, and if it lies within the lower and upper bounds, the result would be inconclusive. As a sample size of this study is relatively small (38 observations), the study used the critical values reformulated by Narayan (2004) which was developed based on the sample size ranging from 30 and 80 observations rather than the reported value of Pesaran et al.(2001) which is appropriate for relatively a large sample size, for observations ranging from 500 and more(Pesaran et al.,2001)

Then ,to check the verifiability of the estimated long run model, a number of diagnostic tests has been undertaken since it is required to check the standard property of the ARDL estimated ARDL model in priority of doing any analysis through Serial correlation test (Brush \& Godfray LM test),Functional form (Ramsey's RESET) test, Normality (Jaque-Bera test), and Hetroskedasticity test.In order to reject or accept the null hypothesis, one can decide by looking the p-values associated with the test statistics. Specifically, the null hypothesis is rejected when the p-value are smaller than the standard significance level (that is, 5\%).

In addition to the above diagnostic tests, the stability of long run estimates has been also tested by applying the cumulative sum of recursive residuals (CUSUM) and the cumulative sum of squares of recursive residuals (CUSUMSQ) test as such tests are also recommended by Pesaran et al. (2001).Consequently, the model faces a parameter instability problem if the CUSUM ; and or the CUSUMSQ plot(s) cross the lower and upper boundary of the plot at the given level of significance, and the model is dynamically stable otherwise.

After confirming the existence of long run relationship among the variables, the following stable long-run ARDL model was estimated

$$
\begin{aligned}
& \ln R G D P t=\beta 0+\sum_{i=1}^{p} \beta 1 \ln R G D P t-i+\sum_{i=0}^{p} \beta 2 \ln P o P n t-i+\sum_{i=0}^{p} \beta 3 O p n t-i+\sum_{i=1}^{p} \beta 4 G t-i+\sum_{i=0}^{p} \beta 5 X t-i \\
& +\sum_{i=1}^{p} \beta 6 M t-i+V t .
\end{aligned}
$$

Where $V t$ is stochastic variable to accommodate the influence of other determinants of economic growth not included in the model in the long run and the remaining terms are as previously defined.

\subsubsection{Estimating the Error Correction Model (ECM) from the ARDL}

Estimating a dynamic equation in the levels of the variables is problematic and differencing the variable is not a solution; so any information about the long run is removed. Therefore, the more suitable approach is to convert the dynamic model into an error correction model (ECM).It shown that this contains information on both the short run and long run properties of the model, with disequilibrium as a process of adjustment to the long run 
(Harris, 1999).

The error correction (EC) representation of the ARDL model estimated in (3.7) is expressed as:

$$
\Delta \ln R G D P t=\beta 0+\sum_{i=1}^{p} \beta 1 \Delta \ln R G D P t-i+\sum_{i=1}^{p} \beta 2 \Delta \ln P o P n t-i+\sum_{i=1}^{p} \beta 3 \Delta \ln O p n t-i+\sum_{i=1}^{p} \beta 4 \Delta \ln G t-i+
$$

$$
\sum_{i=1}^{p} \beta 5 \Delta \ln X t-i+\sum_{i=1}^{p} \beta 6 \Delta \ln M t-i+\delta E C M(-1)+\eta t
$$

ere $\operatorname{ECM}(-1)$ is error correction term lagged by one period. The error correction term (ECT) is derived from the corresponding long run model whose coefficients are obtained by normalizing the following equation:

$E C M=\operatorname{lnRGDPt}-\left[\operatorname{lnRGDPt}=\beta_{0+} \sum_{i=1} p \beta_{1} \operatorname{lnRGDP}_{\mathrm{t}-\mathrm{i}} \sum_{i=0} p \beta_{2} \operatorname{lnPoPt}-i+\sum_{\mathbf{i}=0} \boldsymbol{p} \beta_{3} \ln O P N t-i+\sum_{i=0} \boldsymbol{p} \beta_{4}\right.$ $\left.\ln G t-i++\sum_{i=0} \boldsymbol{p} \beta_{5} \Delta \ln X t-i+\sum_{i=0} p \beta_{6} \ln M t-i\right]$.

Where all terms are as defined before and the $\boldsymbol{\delta}$ is error correction parameters that measure the speed of adjustment towards the long run equilibrium within a year. In other words, the existence of an error-correction term among a number of co-integrated variables implies that changes in the dependent variable are a function of both the level of disequilibrium in co-integration relationship (represented by the ECM) and the changes in explanatory variables.

\subsubsection{Granger Causality Test: The TYDL Approach}

Causality test is important to determine whether one time series is useful in forecasting another or not (Enders, 1995) and following (Guajarati, 2004), there are four cases of causality considered:(1)Unidirectional causality from population growth to economic growth is indicated if the estimated coefficients on the lagged value of population growth are statistically different from zero as a group and the set of estimated coefficient on the lagged values of economic growth are not statistically different from zero as a group(2)Unidirectional causality from economic growth to population growth exists if, the estimated coefficient of lagged value of economic growth is different from zero as a group and the set of the estimated coefficient of the lagged values of population growth are not different from zero as a group(3)Feedback or Bilateral causality from population growth to economic growth and economic growth to population growth, when the set of coefficient of the lagged value of both variables are statistically significant in both regression equations(4)Independence, suggested when the set of lagged value of population growth and economic growth coefficients are not statistically significant in both regressions. Granger causality of population growth on economic growth or economic growth on population growth is absent, when lagged values of population growth or economic growth add no information on each other.

The study adopted the TYDL approach of Toda and Yamamoto (1995) and Dolado and Lutkepohu (1996).This approach has many advantages over the other methods of testing Granger non-causality. The TYDL approach is applicable irrespective of integration and co-integration properties of the model. The TYDL method better controls the type I error probability than other methods based on the VAR and VECM.

The basic idea behind the TYDL is to artificially augment the correct VAR order, $\mathrm{k}$, with $\mathrm{d}_{\max }$ extra lags, where $\mathrm{d}_{\max }$ is the maximum likely order of integration of the series in the VAR system. Thus, the following lag augmented VAR equation is specified for the population and RGD:

$$
\begin{aligned}
& \ln R G P t=\beta 10+\sum_{i=1}^{p} \theta 1 i \ln R G D P t-i+\sum_{i=p+1}^{p+d \max } \Omega 1 i \ln R D P t-i+\sum_{i=1}^{p} \delta 1 i \ln P o P t-i+ \\
& \sum_{i=p+1}^{p+d \max } \omega 1 i+u t \\
& \ln P o P t=\beta 20+\sum_{i=1}^{p} \theta 2 i \ln R G D P t-i+\sum_{i=p+1}^{p+d \max } \Omega 2 i \ln R D P t-i+\sum_{i=1}^{p} \delta 2 i \ln P o P t-i+ \\
& \sum_{i=p+1}^{p+d \max } \omega 2 i+v t
\end{aligned}
$$

From equation(3.10)\&(3.11), Casulity from $\ln$ Pop to $\operatorname{lnRGD}$ implies: $\delta 11=\delta 12=\ldots \delta 1 \mathrm{P} \neq 0 \&$ similarly, Causality from lnRGDP to lnPOP implies: $\theta 21=\theta 22=\ldots . \quad \theta 2 \mathrm{P} \neq 0$

Accordingly, Granger causality is tested using Modified Wald(MWald) test which is theoretically very simple, as it involves estimation of a VAR model augmented in straight ward way.

\subsubsection{Impulse Response Functions (IRFs) and Variance Decompositions}

In empirical research, it is often necessary to know the response of one variable to an impulse in another variable in a system that involves a number of further variables as well. Thus, one would like to investigate the impulse response relationship between two variables in a higher dimensional system (Lutkepohi, 2005).To this end, generalized impulse response which is invariant to the ordering of the variables in the VAR has been used in this 
study.

The results of VAR model estimated in equation (3.9) and equation (3.10) were not interpreted like ordinary regression equations as they were not derived from structural equations as of (Enders ,1995). They were used for the generation of both the impulse response functions and for conducting the variance decomposition analysis, which will depict the effects of population growth on economic growth.

To infer the degree of erogeneity of the variables beyond the sample period, the decomposition of variance which measures the percentage of a variable's forecast error variance that occurs as a result of a shock from a variable in the system should be considered(Nayaran,2004). The orthogonal zed forecast error variance decompositions are not invariant to the ordering of the variables in the VAR, the generalized forecast error variance decomposition which is invariant to the ordering of the variables in the VAR system is used in this study.

\section{Results and Discussions}

\subsection{Descriptive Statistics Results}

Before directly going to the econometric estimation, it is often better to have a look at the descriptive statistics of the variables under consideration. This is crucial because these statistics summarize the statistical properties of the series in the model such that some explanations about the behavior of the series can be offered at glance; Thus, Table 3.1 below summarizes the descriptive statistics results:

Table 3.1 Descriptive/Summary Statistics Results

\begin{tabular}{|l|l|l|l|l|l|l|}
\hline \multicolumn{1}{|c|}{ Summary -Statistics } & RGDPt & Xt & Mt & PoPnt & OPnt & Gt \\
\hline Mean & 308031.5 & 14342101 & 62990200 & 64431246 & 30.96216 & 49159.97 \\
\hline Median & 178512.7 & 3864320 & 11438661 & 62707399 & 26.82000 & 14677.22 \\
\hline Maximum & 1577468 & 63685744 & $3.53 \mathrm{E}+08$ & $1.02 \mathrm{E}+08$ & 70.84000 & 264342.3 \\
\hline Minimum & 101802.6 & 279026.0 & 1384234 & 35239917 & 9.0900000 & 2465.456 \\
\hline Std.Devation & 329692.3 & 21764786 & $1.05 \mathrm{E}+08$ & 20487515 & 15.19319 & 76954.31 \\
\hline Skewness & 2.703288 & 1.465711 & 1.827223 & 0.229593 & 0.971331 & 1.8554517 \\
\hline Kurtosis & 10.14794 & 3.409370 & 5.038985 & 1.816843 & 3.282234 & 5.029305 \\
\hline Jarque-Bera & 123.8330 & 13.50626 & 26.99833 & 2.483183 & 5.940948 & 27.55732 \\
\hline Probablity of J-B & 0.000000 & 0.001167 & 0.000001 & 0.288924 & 0.051279 & 0.000001 \\
\hline Sum & 11397164 & $5.31 \mathrm{E}+08$ & $233 \mathrm{E}+09$ & $2.38 \mathrm{E}+09$ & 1145.600 & 1818919 \\
\hline Sum Sq Dev & $3.91 \mathrm{E}+12$ & $1.71 \mathrm{E}+16$ & $3.96 \mathrm{E}+17$ & $1.51 \mathrm{E}+16$ & 8308.894 & $2.13 \mathrm{E}+11$ \\
\hline Observations & 37 & 37 & 37 & 37 & 37 & 37 \\
\hline
\end{tabular}

Source: Author's Computation 2018/19

\subsection{Unit Root Testing}

As presented in from Table 3.2 below, the PP tests are carried out for two alternative specifications; with constant but no trend; and with constant and trend.

The PP test result shows that the series except the government expenditure are integrated with same order. That is, real GDP growth $(\operatorname{lnRGDP})$, population growth $(\ln \mathrm{PoPn})$, export growth $(\ln \mathrm{X})$ and import growth $(\ln \mathrm{n})$ are $I(1)$ (that is, difference stationary variables and government expenditure growth(lnG) is stationary at level. Consequently, it is clear that none of the variables under the consideration are integrated of order two I (2). It is also clear that the series are integrated of mixed order as government expenditure growth is $\mathrm{I}[0]$ and the remaining other variables are I[1].This, implies that the ARDL co-integration testing technique proposed by Pesaran et al.,(2001) and adopted by this study is quite appropriate. 
Table 3.2 Results for the PP Unit Root Test

\begin{tabular}{|c|c|c|c|}
\hline $\begin{array}{l}\text { Variables (at level and first } \\
\text { difference) }\end{array}$ & $\begin{array}{l}\text { t-Statistics } \\
\text { (with drift) }\end{array}$ & $\begin{array}{l}\mathrm{t}-\text { Statistics } \\
\text { (with drift and trend) }\end{array}$ & $\mathrm{I}[]$ \\
\hline $\ln R G D P$ & 4.145 & 4.886 & not [0] \\
\hline$\Delta \operatorname{lnRGDPt}$ & $-34.946 * * *$ & $-42.501 * * *$ & $\mathrm{I}[1]$ \\
\hline $\ln \mathrm{PoPt}$ & -42.490 & -38.914 & not [0] \\
\hline$\Delta \ln \mathrm{POPt}$ & $-58.525 * * *$ & $-58.659 * * *$ & $\mathrm{I}[1]$ \\
\hline $\ln G t$ & $1.281 * * *$ & $-2.729 * * *$ & $\mathrm{I}[0]$ \\
\hline $\ln \mathrm{Xt}$ & 0.384 & -5.494 & not I $[0]$ \\
\hline$\Delta \ln X t$ & $-38.213 * * *$ & $-38.582 * * *$ & $\mathrm{I}[1]$ \\
\hline $\ln \mathrm{Mt}$ & 0.310 & -12.299 & not I $[0]$ \\
\hline$\Delta \operatorname{lnMt}$ & $-52.442 * * *$ & $-51.451 * * *$ & $\mathrm{I}[1]$ \\
\hline $\operatorname{lnOPnt}$ & 0.243470 & -3.293397 & not I $[0]$ \\
\hline$\Delta \operatorname{lnOPnt}$ & $-3.171545 * * *$ & $-3.297730 * *$ & $\mathrm{I}[1]$ \\
\hline
\end{tabular}

$* * *$ Sign indicates the rejection of the null hypothesis of non-stationary at $1 \%$ significance level and $\Delta$ denotes first difference.

Source: Author's Computation 2018/19

\subsection{Coefficients and Residual Diagnostic Testing Results}

The Brush Godfray LM test failed to reject the null hypothesis of no serial correlation for the reason that that the p-value associated with test statistic is greater than the standard significant level (that is, 0.973243 exceeds 0.05 ).

\subsection{Coefficients and Residual Diagnostic Testing Results}

Table 3.3 Coefficients and Residual Diagnostics Test Results

\begin{tabular}{|l|l|}
\hline Test & F-Version Test-Statistics \\
\hline A: Serial Correlation & Fcal $=0.973243[0.4864]$ \\
\hline B: Functional Form & Fcal $=2.275173[0.1657]$ \\
\hline C: Normality & Jarque-Berra $=1.643978[0.43$ \\
\hline D: Heteroskedasticity & Fcal $=0.559880[0.8766]$ \\
\hline R -Squared $=0.998 \quad$ Adjusted R-Squared $=0.997$ \\
DW $=2.23$ \\
A: Lagrange multiplier test of residual serial correlation \\
B: Ramsey's RESET test using the square of the fitted values \\
C: Based on a Histogram test of Skewness and kurtosis of residuals \\
D: Based on the regression of squared residuals on squared fitted values
\end{tabular}

Source: Author's Computation 2018/19

As 0.1657 exceeds 0.05 , the Ramsey's RESET test can not reject the null hypothesis of the functional form of the model which says that the model is correctly specified. In other words, One cannot reject the null hypothesis for Ramsey's RESET test, which tests whether the model suffers from omitted variable bias or not. The test result indicates that the model is correctly specified.

The third diagnostic test is about the residual. As the result indicates, one cannot reject the null hypothesis which says that the residuals are normally distributed since the p-value associated with the Jarque-Berra normality test is larger than the standard significance level (that is, 0.439557 is greater than 0.05 ). This indicate that the residual is normally distributed as assumed prior.

The last diagnostic test is for heteroskedasticity. And we cannot reject the null hypothesis of homoskedasticity at 5\% significance level as p-value associated with the test statistics is greater than the standard significance level( that is, 0.8766 is greater than 0.05). This implies that the residual possess time invariant or constant variance. Combining this with the normality test result we can conclude that the residual is a white noise.

\subsection{Testing Results of Model (Parameter) Stability Using CUSUM and CUSUMSQ Tests}

The test finds serious parameter instability if the cumulative sum goes outside the area (never returns back) between the two critical lines and or if the CUSUMSQ graph crosses the lower and upper critical limits.

As it can be seen from the first figure, the plot of CUSUM test does not cross the critical limits. Similarly, the CUSUMSQ test shows that the graph does not cross the lower and upper critical limits. So, it is possible to conclude that long run estimates are stable and there is no any structural break in parameters 


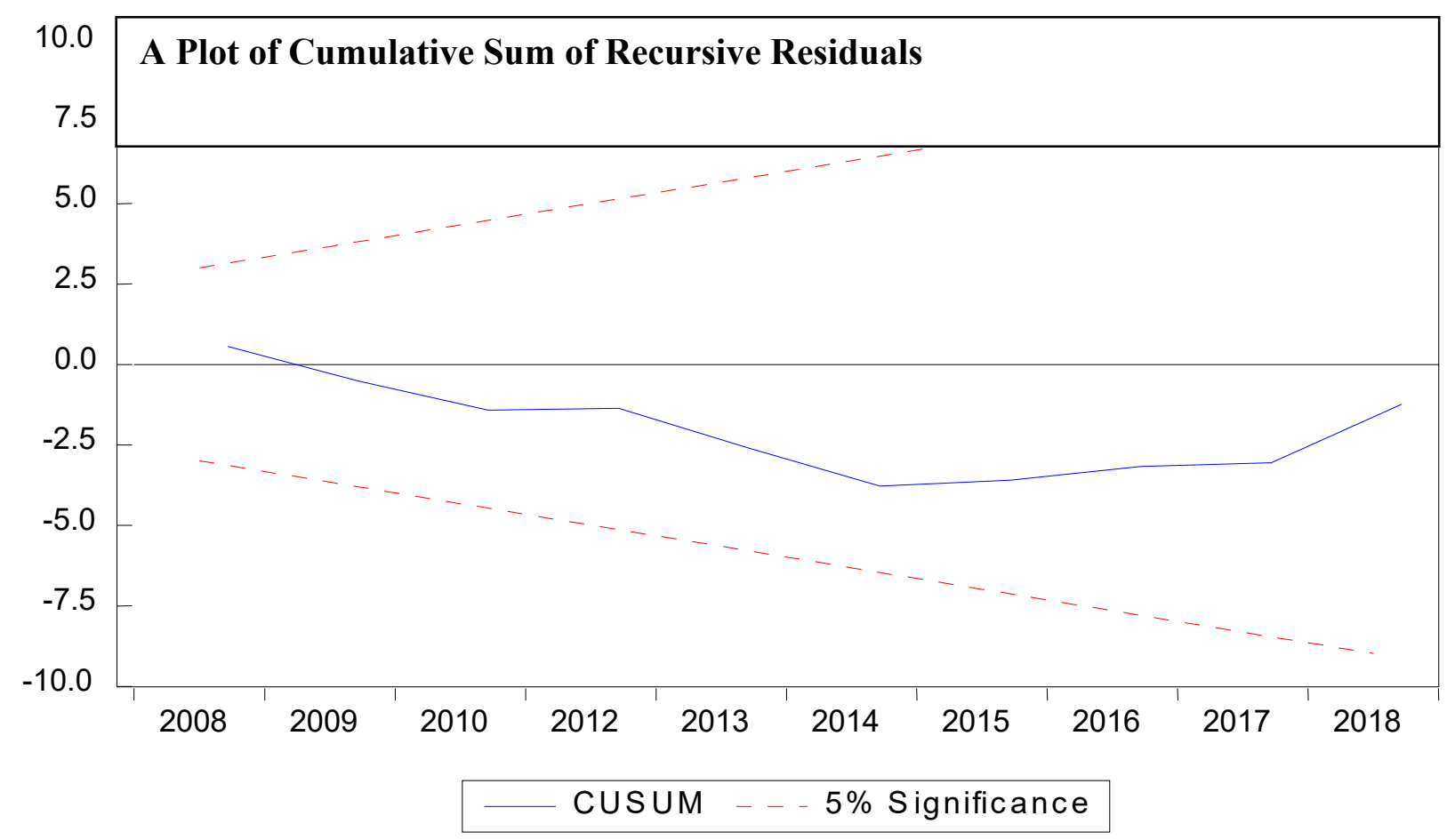

Figure 3.1: Plot of Cumulative Sum of Recursive Residuals (CUSUM) Source: Author's Own Computation 2018

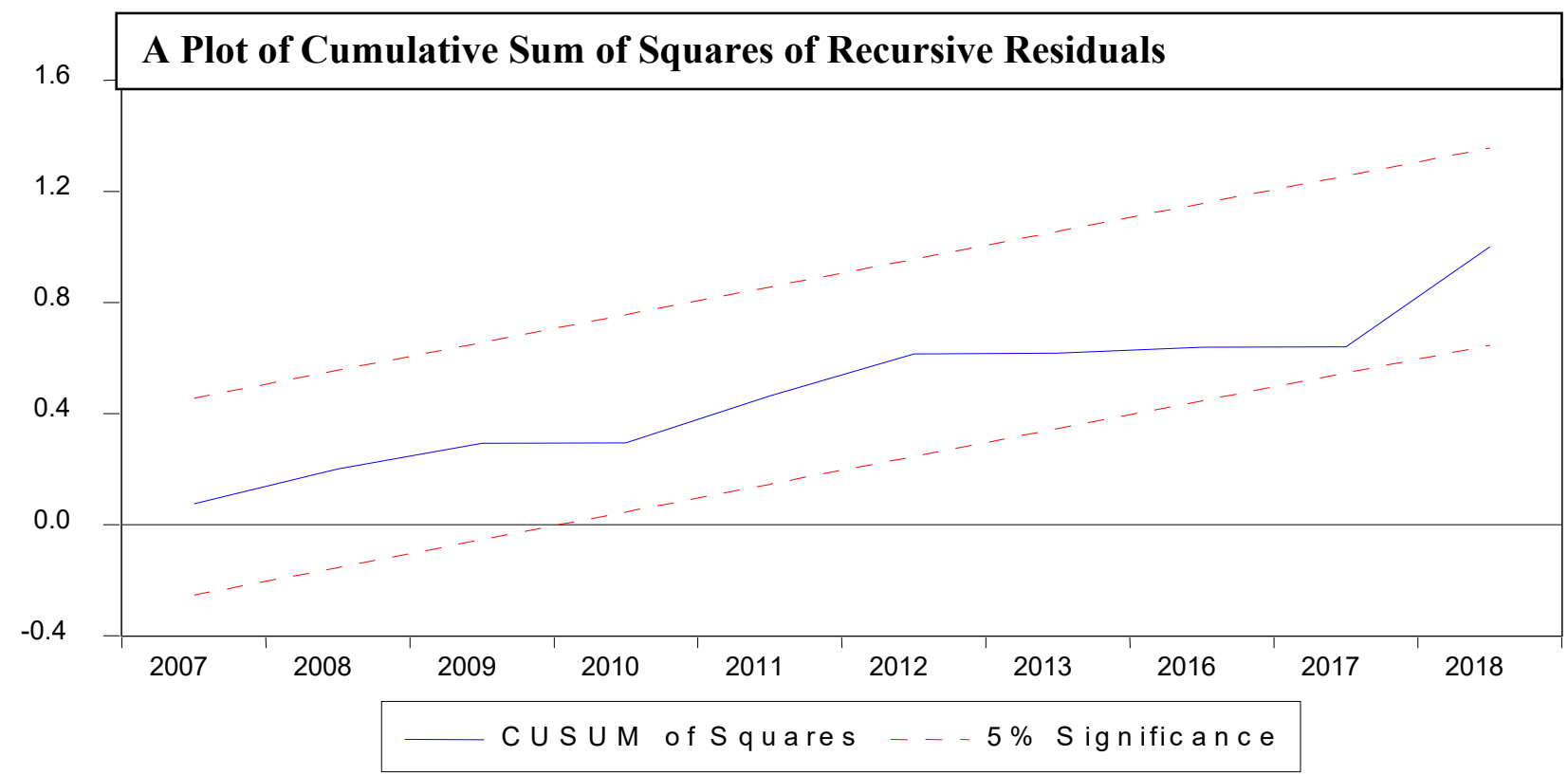

Figure 3.2: Plot of Cumulative Sum of Squares of Recursive Residuals (CUSUMSQ) Source: Author's Own Computation 2018/19

3.6 Bound Testing Result of the Estimated ARDL(1,1) Model

Table 3.4 Bounds Test Result (Eviews10 Output)

\begin{tabular}{|l|l|}
\hline \multicolumn{1}{|c|}{ Description } & \multicolumn{1}{c|}{ Value } \\
\hline Number of Observation & 37 after adjustment for lag \\
\hline Calculated F-Statistics & 8.269899 \\
\hline
\end{tabular}

Source: Author's Own Computation 2018/19 
Table 3.5 critical values for bound test: Case III restricted intercept and Trend

\begin{tabular}{|l|l|l|}
\hline \multirow{2}{*}{ significance level } & Narayan $(2004) \mathrm{CV}, \mathrm{k}=6$ & Upper bound (I(1)) \\
\cline { 2 - 3 } & Lower Bound $(\mathrm{I}(0))$ & 5.669 \\
\hline 1 percent & 2.753 & 4.211 \\
\hline Percent & 2.750 & 3.588 \\
\hline
\end{tabular}

Source: Narayan (2004) critical values

The Narayan(2004) critical values reported on Table 4.5 above were that formulated for the case of ARDL estimated with unrestricted intercept and no trend (that is, case III). Moreover, the Narayan(2004) critical values are the reformulated values for 30 to 80 observations .

The result shows that $\operatorname{lnRGDP}$ and $\ln P o P$ are co-integrated since the F-statistic, also written as $\mathrm{F}_{\text {lnRGDP }}$ (lnRGDP $\mid \ln$ PoP) equals to 8.299899 for the estimated ARDL model with optimum lag order ARDL $(1,1)$ and specified with an intercept and trend is higher than the Narayan (2004) upper bound critical values at 1 percent level of significance.

This implies that the null hypothesis of no long-run relationship is rejected and the alternative hypothesis of long-run relationship is accepted through bound test.

\subsection{Long Run ARDL Model Estimation Result}

So far, it has been confirmed that there is long-run relationship (co-integration) among the variables considered, and that the selected ARDL model passes all the diagnostic tests plus its stability. So, what is next is that estimating long run coefficients ARDL model specified in equation (3.8) to find out the long run relationships among the variables. This is reported in table 3.6 below;

Table 3.6 Estimated Long Run Coefficients for the estimated ARDL $(1,1)$

\section{Dependent variable is InrRGDP}

\begin{tabular}{|l|l|l|l|l|}
\hline Variable & Coefficient & Std. Error & t-Statistic & Probability \\
\hline $\ln \mathrm{X}$ & $0.188664 * *$ & 0.040281 & 4.683745 & 0.0000 \\
\hline $\ln \mathrm{M}$ & $0.921818^{* * *}$ & 0.062288 & 14.79917 & 0.0000 \\
\hline $\ln \mathrm{P}$ & 0.029379 & 0.035988 & 0.816352 & 0.4333 \\
\hline $\ln \mathrm{PoPn}$ & $1.542218 *$ & 0.878418 & 1.755677 & 0.1097 \\
\hline $\ln \mathrm{OPn}$ & $-1.1294411^{* * *}$ & 0.061876 & -18.25282 & 0.0000 \\
\hline $\mathrm{EC}=\ln R G D P-(0.1887 * \ln \mathrm{X}+0.9218 * \ln \mathrm{M}+0.0294 * \operatorname{lnG}+1.5422 * \ln P \operatorname{Pn}-1.1294 * \operatorname{lnOPn}$ & \\
\hline
\end{tabular}

$* * * \& *$ sign denote the significance of the coefficients at $1 \%$ and $10 \%$ significance level, respectively.

Source: Author's Computation 2018/19

Table 3.6 indicates that all the variables entered in the regression except trade openness have the expected signs regardless of their significance level. As it has been discussed in the theoretical and empirical literature parts; the variables; population, import and export have significant positive long run impact on Ethiopian economic growth while the government expenditure has positive but insignificant impact. However, trade openness is found to have significant negative long run impact on Ethiopian economic growth in contrast to what was expected earlier.

The long run coefficient of population growth $(\ln \mathrm{PoPn})$ is 1.542218 and it is statistically significant at 10 percent . Since the growth model is specified in a log-log form, the coefficient of the dependent variable can be interpreted as elasticity with respect of the repressors. Therefore, at citrus paribus, one percent increase in Ethiopian population will lead to 1.542218 percent, that is, more proportionate increase on economic growth, on average, and it is statistically significant.

The result is in-line with the optimist theory of Population .More specifically, the result is consistent with the arguments' of optimistic viewers such as Boserup(1965), Simon and Mercantilists who believed that population growth induces economic growth; by providing the needed consumer demand to generate favorable economies of scale in production to lower production costs, by providing a sufficient and low cost labor supply and thereby reducing cost of production and discouraging the idleness that might become associated with higher wage levels, by putting more pressure on the existing agricultural system and thereby encouraging invention of new technologies and bringing institutional changes.

The existing reality on the ground in the country could also support the result. That is,(1)Ethiopia faces no constraint of natural resources such as land constraint of which was among the main points for Malthusian pessimistic Argument,(2) although it is recently, there has been technological changes such as ; the use of improved seeds, the use of fertilizers and adoption irrigation technologies etc. practiced at large in agriculture sector which is main source of income for more than $80 \%$ of Ethiopian,(3) although agriculture is still a the main contributor to economic growth, its share to GDP has been declining with increase in the share of service and 
industry implying that the agriculture sector has started transformation with the existing increased population ; and (4) the Ethiopian population data shows that the it is growing at decreasing rate which supports the idea of neoclassical growth theory that say lower population growth rate(n) is one of the significant contributor to economic growth. Moreover, the result is consistent with the findings of Kassahun (2014) for the case of Ethiopia (that is, although it is for long run case only), Gideon et al.(2013) for case of Kenya, Nwosu et al.(2014) for the case of Nigeria .

Export growth positively impacts the economic growth of Ethiopia and it is statistically significant at one percent. To be specific, all other things remaining constant, one percentage increase on export in the economy will lead to 0.188664 percent growth in real GDP.

This finding is in-line with a standard propositions of neoclassical growth model type which suggest that good export performance and "outward orientation" make major contribution to economic growth. The empirical findings of many studies such as; Faye (2001),Hailegiorgis(2012) ,Senait (2014) ,Woinshet(2014) among others conducted on the relationship between export and economic growth also collaborate the result.

Import growth also positively impacts the economic growth of Ethiopia and it is statistically significant at one percent. In other words, all other things being equal, a percentage growth in the level of import of the country will lead to 0.921818 percent growth in the Ethiopian economy. This supports the theory of comparative advantage which states that all parties maximize benefit in an environment of unrestricted trade, even if absolute advantages in production exist between the parties and the argument World Trade Organization (WTO) which says that the chief advantage to importing products is an increase in market choices. Empirically, the result is consistent with the findings of studies such as; Bethelehem (2017) and Alemayehu (2013) who found positive and significant relationship between import and economic growth in Ethiopia.

Trade Openness is found to have significant negative impact on economic growth. That is, all others being equal, one percent increase in trade openness measurement (trade liberalization) will lead to 1.2294411 percent decreases in economic growth, on average. This negative relationship supports the result of Estubdink (2014) who found similar sign but insignificant impact of trade openness on economic growth. However, the result contradicts with Yetsedaw(2017) who found that positive relationship between trade liberalization and Economic Growth in Ethiopia .Therefore, it is possible to conclude and that the impact of trade openness on economic growth in Ethiopia is controversial.

Finally, government expenditure is found to have positive but insignificant impact the economic growth of Ethiopia as expected earlier. Most of Studies, for instance, Kojo et al (2012) and Dereje(2012) among others have also concluded that government expenditure has positive but insignificant impact on the economic growth of the country by claiming that it may be due to the un-transparent and unaccountable behavior of the government. The finding of this study supports that as if their claim was true.

\subsection{Error Correction Model (ECM) Estimation Result}

The coefficient of the error correction term indicates that how quickly variables converge to the long equilibrium. Moreover, it should be statistically significant at a standard significant level (that is, p-value should be less than $0.05)$.

It is estimated at negative 0.931244 and it is statistically significant at one percent significance level, and implies a very high speed of adjustment to equilibrium. The minus 0.931244 value implies that about 93.1277 percent of any movements into disequilibrium are corrected (adjusted) within one period, and thus, the total adjustment will take a year and about a month. Said in another way, the coefficient of the error term (ECT) implies that the deviation from long run equilibrium level of real GDP in the current period is corrected by 93.1277 percent in the next period and it is highly significant.

According to Bannerjee et al. (2003) (as cited in Kidanemarim,2014), the highly significant error correction term further confirms the existence of a stable long-run relationship.

The coefficient of determination (R-squared) which measure the "goodness of fit" of the model is also very high (that is, 0.99). It indicates that $99 \%$ of variations in real GDP are explained by the variations in all of the repressors included in the model. Thus, only about one percent variation in real GDP is left unexplained which in turn has been already captured by the error term. In addition, the DW statistic does not suggest autocorrelation and the F-statistic is quite robust implying that all the repressors are jointly significant to explain real GDP.

The estimated short-run dynamic model reveals that trade openness (lnOPn), export, import and population are highly significant variables in the model. One period lagged value of import and trade openness also significantly affect real GDP.

When the short run impact of population on economic growth is interpreted; other things remaining constant, a percentage increase in Ethiopian population will increase real GDP by 0.55 percentages, on average. This implies that population growth has significant positive impact on economic growth of Ethiopia both in long run and short run. This is in-line with prior expectation and is also consistent with the existing wisdom.

When we compare and contrast the long run and the short run impacts of each variable, all of the variables 
except the government expenditure significantly impact the economic growth in both periods with the same signs. Specifically, population, import and export are found to have significant and positive impact on economic growth both in the short run and long run while the variable trade openness has significant and negative impact. Nevertheless, the government expenditure does not have any impact on economic growth.

Table 3.7: Error Correction Representation of the estimated ARDL Model

\begin{tabular}{|c|c|c|c|c|}
\hline Variable & Coefficient & Stand. Error & $\mathrm{t}$-Statistic & Probability \\
\hline Constant & $-25.85358 * * *$ & 2.987537 & -8.653809 & 0.0000 \\
\hline Trend & $-0.048970 * * *$ & 0.006128 & -7.991503 & 0.0000 \\
\hline$\Delta \ln X$ & $0.197518 * * *$ & 0.007544 & 25.78457 & 0.0000 \\
\hline$\Delta \ln X(-1)$ & -0.004991 & 0.010415 & -0.450431 & 0.06620 \\
\hline$\Delta \ln \mathrm{M}$ & $0.676306 * * *$ & 0.027426 & 24.65942 & 0.0000 \\
\hline$\Delta \ln M(-1)$ & $-0.183353 * * *$ & 0.031605 & -5.801355 & 0.0002 \\
\hline$\Delta \ln P O n P$ & $0.549645 * * *$ & 0.2211531 & 2.598417 & 0.0003 \\
\hline$\Delta \ln \mathrm{POP}(-1)$ & -0.373298 & 0.251090 & -1.486711 & 0.0266 \\
\hline$\Delta \ln \mathrm{OP}$ & $-0.885214 * * *$ & 0.031008 & -28.548417 & 0.1679 \\
\hline$\Delta \operatorname{lnOPn}(-1)$ & $0.221446^{* * *}$ & 0.0 .038705 & 5.721419 & 0.0000 \\
\hline $\operatorname{ECM}(-1)$ & $-0.931244 * * *$ & 0.107942 & -86.27230 & 0.0000 \\
\hline \multicolumn{5}{|c|}{$\begin{array}{lr}\text { R-squared: } 0.995885 & \text { F-Statistics : } 213.5909[0.0000 \\
\text { Adjusted R-Squared:0.991253 } & \text { DW-statistic }=2.235308\end{array}$} \\
\hline
\end{tabular}

*** Sign denote the significance of the coefficients at 1\% significance level

Source: Author's Computation 2018/19

3.9 The TDYL Causality Testing Result

Table 3.8 VAR Lag Order Selection Criteria

\begin{tabular}{|l|l|l|c|}
\hline Lag & Log & LR & FPE \\
AIC & LSC & HQ & \multicolumn{2}{|c|}{} \\
\hline 0 & -4.322413 & NA & 0.351245 \\
\hline 1 & 0.434918 & 0.381950 & $-9.548258^{*}$ \\
& 179.5267 & $337.0567^{*}$ & $-9.640373^{*}$ \\
\hline
\end{tabular}

*indicates lag order selected by the criterion, LR is sequential modified LR test statistics (each test a $5 \%$ level), FPE is final prediction error, AIC is Akaike Information Criterion, SC is Schewarez Information Criterion and HQ is Hannan-Quinn information criterion.

Source: Author's Computation 2018/19

As it can be seen from Table 3.8, the optimal lag length is one. And since the variables become stationary after first differencing as suggested by PP test, it implies that $\mathrm{d}_{\max }$ is also one. Therefore, the researcher estimated a system of VAR in levels with a total of $\left(\mathrm{d}_{\max +\mathrm{k}}=1+1\right)$ which is 2 lags where $\mathrm{k}$ is the lag length selected by information criteria. Using this information, the system of equations (that is, equation 3.10 and 3.11 ) is jointly estimated.

And then, following the TYDL approach, the augmented VAR of order two is estimated and the Wald test is performed only on the coefficients of first lag.

Table 3.9 Estimates of Long Run Granger Causality based on TYDL Approach (Eviews10 Output)

\begin{tabular}{|l|l|l|l|}
\hline Null Hypothesis & Chi-sq $\left(X^{2}\right)$ & Prob. & Decision \\
\hline lnPOP does not Granger Cause lnRGDP & $6.079209^{* *}$ & 0.4144 & Reject Ho \\
\hline LnRGDP does not Granger Cause lnPOP & $12.52947^{*}$ & 0.0511 & Reject Ho \\
\hline
\end{tabular}

**and* indicates the significance at $5 \%$ and $10 \%$, respectively

Source: Author's Computation 2018/19

The TYDL Granger Causality test results suggested that there is bi-directional causality running from economic growth to population and from population growth to economic growth. The result is supports the finding of Gideon et al. (2013) and it may also support the result of Becker (1981) who found out that when a country is in a demographic transition, population growth increases with an increase in economic growth in the short run, thereby would suggest that Ethiopia in demographic transition.

Considering the causality from economic growth to population growth first, it is likely that in the short term, high economic growth in a developing country will increase population growth, mainly through reducing mortality rates. This is the typical process of a country beginning a demographic transition which initially increases population growth rates. In the long term, however, it is very likely that economic growth will reduce population growth as wealthier parents choose smaller families which will over time reduce population growth as in the case of rich countries. 
On the other hand, the causality from population growth to economic growth could be attributed to due to increased expenditure of government on different programs and on the increased demand for basic infrastructure services.

\subsection{The Generalized Impulse Response Analysis Results}

(a).The impact of Economic growth on population growth.

Appendix A.1 illustrates the estimated generalized impulse response functions of variables population growth (lnRGDP) for ten years. A one standard deviation disturbance originating from economic growth results in an approximately 1.4 percent increase in population in the first period and then it continuously increases 3.1 percent in $5^{\text {th }}$ period and finally reaches 5.2 percent in the tenth period. This shows that the impact of economic growth on population growth is permanent. This result is in support of Becker (1981) who found out that when a country is in a demographic transition, population growth increases with an increase in economic growth in the short run.

\section{(b).The impact of population growth on economic growth}

Appendix A.2 illustrates the estimated generalized impulse response functions of variables population growth ( $\ln P o P n)$ for ten years. A one standard deviation disturbance originating from population growth results in an approximately 2.3 percent increase in economic growth in the first year, by 4.1 percent in the next period and reaches 5.7 percent in the tenth period by growing continuously. This indicates that the impact of population on economic growth is does not die out with the increase in time horizon.

\subsection{Variance Decompositions Analysis Results}

The results of Variance Decomposition analysis of economic growth rate show that all the variations in economic growth rate were due to its own shocks at 100 percent in the first year implying that population growth did not contribute at all to the variations in economic growth in the first year (see Appendix B.1). The variations of own shocks in economic growth reduced to 94.75 percent in the second year. In the third year the variations further reduced to 89.3 percent and continued to reduce as the forecasting horizon increased. The forecast error decomposition technique continues to reveal that after the first year, the variations in economic growth are dependent on its own composition and variations in population growth.

Appendix B.2 presents the generalized forecast error variance decomposition for population growth ( $\ln$ RGDP).The result also revealed that the effect of population growth in the system increased with the increase in forecast period. This implies that economic growth has feedback effects with population growth and the effects are multidirectional. This collaborates with the TYDL causality test result which witnessed the existence of bidirectional causality between population growth and economic growth.

\section{Conclussion and Policy Implications}

\section{1 Conclusion}

The study examined the impact population growth on economic growth in Ethiopia for the period 1980/812016/18 using a recent and popular methodology of ARDL Bounds Testing. It study also indentified the direction of dynamic causality between population growth and economic growth using TYDL approach.

The empirical results revealed that population growth has significant positive relationship with economic growth both in the short run and long run. More specially, at citrus paribus, one percent increase in Ethiopian population will lead to 1.1294411 percent (that is, more than proportionate) increase on economic growth in the long run. Again, all other things being equal, one percentage increase in Ethiopian population will increase its real GDP by 0.55 percentages, on average, in the short run. The results of impulse response function supported these results by showing that impact of population on economic growth is permanent. Moreover, the results of YTDL causality testing approach suggest that there exists bi-directional causality when causality is assumed to run from population to economic growth or from economic growth to population growth. Overall, the relationship between population and economic growth is strong and positive in Ethiopia over the periods of the study.

\subsection{Policy Implications}

The findings give support to the population-driven economic growth hypothesis that states the population growth in a country's promotes its economic growth and development. The findings also suggests that Ethiopia seems to be in the second stage of the demographic transition, called post Malthusian regime, in which the relationship between economic growth and population growth remains strong and positive

Therefore, a carefully planned population growth strategy coupled with efficient and effective institutional and economic policy changes could be beneficial. A well managed population expansion will ensure that both the population and the economy are complementing each other without concerns that population expansion will lead countries to famines and lack of other socio-economic facilities since it's the inadequate and ineffective government policies, rather than population growth which are responsible for the woes including, famines that 
devastate most developing nations.

The government should also put measures to sustain the existing economic growth which has been growing at a higher rate than the population growth. This will ensure that the increasing demand of goods and services arising from the population growth is met. Having a larger, healthier, and better-educated workforce will only bear economic fruit if the extra workers can find jobs. As a result, open economies, flexible labour forces, and modern institutions that can gain the confidence of the population and markets alike may help country reap the potential benefit created by its demographic transition.And the impact of the other dimensions population such as population density, size, structure and population aging on economic growth requires in-depth investigations.

\section{References}

Alemayehu S.(2013).The Relationship between Import and GDP Growth in Ethiopia: An Empirical Analysis.EEA Publication Vol.-II

Barro R J. (2013),'Inflation and Economic growth”, Annuals Of Economics And Finance 14-1, 85-109 (2013), Department of Economics Litterateur Centre 120 Harvard University Cambridge, MA

Becker, GS. (1991) "The Economic Way of Looking at Life" Becker [1981, 1991, pp.9-13]).

Bethelehem T.(2017).The Relationship between Import,Exports and Economic Growth in Ethiopia:IJIR.Vol3,Issue-1(2017).

Boserup, E. (1965): The Conditions of Agricultural Growth: The Economics of Agrarian Change under Population Pressure. London

CIA WFB(2018):Overview Ethiopian Economy

CSA Ethiopia, reports of the 1994, 2006 and 2007 population and housing census and 2012 inter-censual survey

Dejene A.(2002): Agricultural Growth, Population and Environmental Nexus. Paper prepared to the tenth Annual Conference on the Ethiopian Economy, Adama, Ethiopia.

Dereje M.(2012).The Impact of Goverment Expenditures on Growth in Ethiopia.Jimma University 73.Jimma:Jimma University.

Dolado J.,Lutkepohi H.(1996).Making Wald tests work for cointegrated VAR systems.Econom.Rev.15:369386.DOI:10.1080/0747939608800362

Enders W.,(1996):Applied Econometric Time Series. Lowa State University: John Wiley \& Sons INC."

Gedeon K. ,Gideon Kiguru T. , Obere A. and Gachanja P.(2013).:The Impact of Population Change on Economic Growth . IJEMS. Vol. 2, pp. 43-60

Gujarati ,D. (2004) Basic Econometrics, Fourth Edition, the McGraw-Hill Companies

Hailegiorgis B. (2012), ), "The Effect of Export-Led Growth Strategy on the Ethiopian Economy", American Journal of Economics 2012, Vol 2 No 3: p50-56

Harris, R. (1999):"Using Co-integration Analysis in Econometric Modelling .London, prentice hall."

Jhingan (2002): The Economics of Development and Planning, New Delhi, India

Kassahun A. (2014): Impact of Population Growth on the Ethiopian Economic Performance; A Project Submitted to the School of Graduate Studies of Addis Ababa University, Addis Ababa, Ethiopia

Keynes, J.M. (1936):"General theory of employment, Interest and Money; London Macmillan."

Kidanemariam G.(2013):The Impact of Human Capital Development on Economic Growth In Ethiopia: Evidence from ARDL Approach to Co Integration. Development economics: Ethiopian Civil Service University.

Kojo M.(2012).Goverment Expenditure and Economic Growth.Ethiopian Exprience,1950-2007:JDA.Vol-47.

Lutkepohi ,H.(2005).New Introduction to Multiple Time Series Analysis.Berlin:Springer

Malthus, T.R. (1798): An Essay on the Principles of Population, (Cambridge: Cambridge University Press.

Mankiw, NG.(2009):Macroeconomics; $7^{\text {th }}$ edition ;Harvard University; Worth Publishers

Martin P. (2009) "Demographic and Economic Trends: Implications for International Mobility" United Nations Development Program Human Development Reports. Research Paper 2009/17

Narayan K. (2004)," Reformulating Critical Values for the Bounds F-statistics Approach to Co integration: An Application to the Tourism Demand Model for Fiji”, Discussion Papers No 02, Monash University, Victoria, Australia.

Nwosu, C., Dike, A. and Okwara, K., (2014): The Effects of Population Growth on Economic Growth in Nigeria

Obere Almadi ,Gideon Kiguru Thuku and Gachanja Paul:The Impact of Population Change on Economic Growth. IJEMS. Vol. 2, pp. 43-60

Pesaran MH,Shin Y,Smith RJ(2001).Bounds Testing Approaches to the Analysis of Levels Relationships.J.Appl.Econom.,16:289-326.

Pesaran, M. and Shin, Y. (1999), "An Autoregressive Distributed Lag Modeling Approach to Co integration Analysis" in S. Strom, Econometrics and Economic Theory in the 20th Century: The

Philips, PC,Toda HY.(1994).Vector Autoregression and Causality: A Theoritical Overview and Simulation Study.Econometric Review,13(2):259-285 
Philips, PC,Toda ,H.Y(1993).Vector Autoregression and Causality.Econometrica,61(6):1367-1393

Senait G.(2014).The Contribution of Export Earnings to Economic Growth of Ethiopia: a trend analysis : JAD 4(1) 2014

Simon, J. L. (1992) Population and Developing Countries, Princeton University Press: Princeton, New. Jersey

Toda, H. Dolado Y., \& Yamamoto, T. (1995). Econometrics, 66, 225-250.

Todaro M. (2004), Economic Development, $11^{\text {th }}$ ed., New York, London

Trading Economics, reviewed on December 22/2018

Verbeek M.(2004):A Guide to Modern Econometrics(2 ${ }^{\text {nd }}$ ed.),Erasmus University Rotterdam.

Woinshet B.(2014).The Relationship between Export and Economic Growth in Ethiopia. MSc. Thesis,Addis Ababa University

\section{Appendixes}

Appendix A.1 Generalized Impulse response one Standard Error (SE) Economic Growth

\begin{tabular}{|l|c|c|}
\hline Period & lnRGDP & $\ln P$ Pn \\
\hline 1 & 0.043966 & 0.014070 \\
2 & 0.044244 & 0.015760 \\
3 & 0.022088 & 0.018269 \\
4 & 0.012445 & 0.028721 \\
5 & 0.021041 & 0.031556 \\
6 & 0.013556 & 0.033022 \\
7 & 0.017173 & 0.038128 \\
8 & 0.026683 & 0.041221 \\
9 & 0.025376 & 0.047304 \\
10 & 0.021077 & 0.052300 \\
\hline
\end{tabular}

Appendix A.2 Generalized Impulse response one SE for Population Growth

\begin{tabular}{|l|r|r|}
\hline Period & $\ln$ RGDP & $\ln$ PoPn \\
\hline 1 & 0.023966 & 0.041407 \\
2 & 0.034244 & 0.04276 \\
3 & 0.036208 & 0.488269 \\
4 & 0.037244 & 0.051872 \\
5 & 0.041041 & 0.05560 \\
6 & 0.041355 & 0.0566302 \\
7 & 0.042717 & 0.056642 \\
8 & 0.052668 & 0.0567211 \\
9 & 0.056537 & 0.0568040 \\
10 & 0.057207 & 0.0473000 \\
\hline
\end{tabular}

Appendix B.1 Generalized forecast error variance for economic growth (InRGDP)

\begin{tabular}{|l|l|l|}
\hline Horizon & lnRGDP & lnPoP \\
\hline 1 & 100.000 & 0.000000 \\
2 & 94.75217 & 5.247835 \\
3 & 89.30721 & 10.69279 \\
4 & 86.59165 & 13.40835 \\
5 & 80.53165 & 19.46835 \\
6 & 73.88199 & 26.111801 \\
7 & 71.27054 & 29.48604 \\
8 & 70.51396 & 29.48604 \\
9 & 68.59155 & 31.40845 \\
10 & 66.69597 & 33.403 \\
\hline
\end{tabular}


Appendix B.2 Generalized forecast error variance for Population Growth (InPoPn)

\begin{tabular}{|l|c|c|}
\hline Horizon & lnRGDP & $\ln$ POP \\
\hline 1 & 0.102390 & 99.89761 \\
2 & 10.67457 & 89.32543 \\
3 & 13.49168 & 86.50832 \\
4 & 11.27737 & 88.72630 \\
5 & 9.155611 & 90.84439 \\
6 & 7.541822 & 92.45818 \\
7 & 6.819846 & 93.18015 \\
8 & 5.843586 & 94.15641 \\
9 & 5.787776 & 94.21222 \\
10 & 5.8222434 & 94.17757 \\
\hline
\end{tabular}

